\section{OPEN ACCESS}

Edited by:

Dov Borovsky,

University of Colorado Anschutz

Medical Campus, United States

Reviewed by:

Brenda Oppert

United States Department of Agriculture (USDA), United States

Hongbo Jiang,

Southwest University, China

*Correspondence:

Paweł Marciniak

pmarcin@amu.edu.pl

Specialty section:

This article was submitted to Invertebrate Physiology, a section of the journal

Frontiers in Physiology

Received: 11 December 2019

Accepted: 14 April 2020

Published: 12 May 2020

Citation:

Marciniak $P$, Witek $W$, Szymczak M, Pacholska-Bogalska J,

Chowański S, Kuczer M and

Rosiński G (2020)

FMRFamide-Related Peptides

Signaling Is Involved in the Regulation of Muscle Contractions in Two

Tenebrionid Beetles.

Front. Physiol. 11:456.

doi: 10.3389/fphys.2020.00456

\title{
FMRFamide-Related Peptides Signaling Is Involved in the Regulation of Muscle Contractions in Two Tenebrionid Beetles
}

\section{Paweł Marciniak*, Wojciech Witek¹, Monika Szymczak', Joanna Pacholska-Bogalska1, Szymon Chowański ${ }^{1}$, Mariola Kuczer ${ }^{2}$ and Grzegorz Rosiński ${ }^{1}$}

1 Department of Animal Physiology and Development, Adam Mickiewicz University, Poznań, Poland, ${ }^{2}$ Faculty of Chemistry, University of Wrocław, Wroctaw, Poland

Peptidergic signaling regulates various physiological processes in insects. Neuropeptides are important messenger molecules that act as neurotransmitters, neuromodulators or hormones. Neuropeptides with myotropic properties in insects are known as FMRFamide-like peptides (FaLPs). Here, we describe the myotropic effects of the endogenous FaLPs in the regulation of contractile activity of the heart, ejaculatory duct, oviduct and the hindgut in two beetle species, Tenebrio molitor and Zophobas atratus. A putative receptor was identified in silico in both species. Using RT-PCR these putative FaLPs receptors were found in the various tissues of both beetles, including visceral organs. Analysis of the amino acid sequence of the receptor indicated that it is similar to other insect FaLPs receptors and belongs to G-protein coupled receptors. A synthetic FaLP (NSNFLRFa) found as the bioanalogue of both species demonstrated concentration-dependent and organ-specific myoactive properties. The peptide had species-specific cardioactivity, in that it stimulated $Z$. atratus heart contractions, while slightly inhibiting that of T. molitor and had mainly myostimulatory effect on the examined visceral organs of both beetle species, with the lowest activity in the ejaculatory duct of these beetles. The peptide was the most active in the hindgut of both species, but only at high concentration of $10^{-5} \mathrm{M}$. The results suggest that FaLPs are potent modulators of endogenous contractile activity of the visceral muscles in beetles and may indirectly affect various physiological processes.

Keywords: G-protein coupled receptor, visceral organs, FMRFamide-like peptides, neuropeptides, beetles (Coleoptera), heart

\section{INTRODUCTION}

FMRFamide is the four amino acid sequence (Phe-Met-Arg-Phe- $\mathrm{NH}_{2}$ ) first found as an molluscan cardioacceleratory agent (Price and Greenberg, 1977). FMRFamide itself is not present in insects, but the name has been used to describe peptides with a C-terminal RFamide motif, which were grouped together in a family of FMRFamide-like peptides (FaLPs) or FMRFamide-related peptides (FaRPs). The FaLPs "family" originally included N-terminally extended FMRFamides, myosuppressins (MS), neuropeptides F (NPF), and short neuropeptide F (sNPF). These peptides 
now are assigned to separate families, because they are encoded on different genes and have their own receptors. The insect FaLPs therefore comprises only the N-terminally extended FMRFamides (Coast and Schooley, 2011). A variable number of N-terminally extended FMRFamides are present in various insects along with extended IRF/Lamides (Coast and Schooley, 2011).

The physiological activity of insect FaLPs have been studied in different species and were shown to be mainly myoactive, however, with different effectivity. They regulate the heart and other visceral muscles contractility including male and female reproductive tracts (Merte and Nichols, 2002; Sedra and Lange, 2014; Suggs et al., 2016). Other known functions of FaLPs include involvement in regulation of circadian rhythm (Pyza and Meinertzhagen, 2003) and synaptic activity (Marques et al., 2003). Most of the research has been performed on different insect species, such as flies (Merte and Nichols, 2002), locusts (Robb and Evans, 1994), stick insects (Lange et al., 2009), or mosquitoes (Hillyer et al., 2014). However, scarce information is available regarding FaLPs in the largest insect order - the beetles. Thus far, only tetrapeptide FMRFa was shown to stimulate contractions of beetle reproductive tracts (Marciniak and Rosinski, 2010). Thus, the exact physiological role of FaLPs in beetles, as well as in other insects is still unclear.

Recently, due to the involvement of omics technologies, FaLPs precursors have been identified in several beetle species (Pandit et al., 2019). In all studied beetle species, the identified precursors contain several bioanalogues which the C-terminus contains either - FLRFa or - FIRFa (Veenstra, 2019). In tenebrionid beetles, FaLPs precursors' sequences are available for three species: Tenebrio molitor and Zophobas atratus (this study) and the first beetle with complete neuropeptidome Tribolium castaneum ( $\mathrm{Li}$ et al., 2008). In all of these species, the precursor contains six bioanalogues (Figure 1). To evaluate the organspecific myotropic properties of FaLPs in beetles, here, we report the activity of the last bioanalogue from the precursor FMRF6 (NSNFLRFa) which was identical in all three species (Figure 1).

Most of the insect neuropeptides act via $G$ protein coupled receptors (Audsley and Down, 2015). GPCRs have seven $\alpha$ helical transmembrane domains and are, therefore, also called seven transmembrane (7TM) receptors and are one of the most common and important molecules in living organisms
(Hauser et al., 2008). In beetles, a complete set of GPCRs for neuropeptides was first described in T. castaneum (Hauser et al., 2008). In this study, we predicted also the FaLPs receptor (FMRFR) in T. molitor and Z. atratus in order to evaluate whether the observed effects of peptide applications are direct due to ligand receptor interactions.

\section{MATERIALS AND METHODS}

\section{Insects}

Tenebrio molitor adult males (4 weeks post-eclosion) were reared according to a previously described procedure (Rosinski et al., 1978). Zophobas atratus adults (4 weeks post-eclosion) were obtained from a colony maintained at the Department of Animal Physiology and Development, Adam Mickiewicz University, Poznań according to the Quennedy procedure (Quennedey et al., 1995).

\section{Peptides}

Peptide FMRF6 (NSNFLRFa) was synthesized according to the Fmoc procedure, as described previously (Marciniak et al., 2008; Lubawy et al., 2018). Proctolin (RYLPT), used as a control peptide, was obtained from Sigma Aldrich (Germany). The peptides were dissolved in physiological saline appropriate for beetles $\left(274 \mathrm{mM} \mathrm{NaCl}, 19 \mathrm{mM} \mathrm{KCl}, 9 \mathrm{mM} \mathrm{CaCl}_{2}, 5 \mathrm{mM}\right.$ glucose, $5 \mathrm{mM}$, HEPES, pH 7.0) to yield a stock solution of $10^{-3} \mathrm{M}$, and it was stored at $-20^{\circ} \mathrm{C}$. Working dilutions were prepared from a stock solution in a physiological saline.

\section{Transcriptome Sequencing, Database Search, and Sequence Comparison}

Transcriptomic data from T. molitor and Z. atratus were obtained after Illumina Hiseq sequencing of total RNA extracted from the brains $(n=10)$ and retrocerebral complexes $(n=10)$ of adult beetles and sequenced at the Beijing Genomics Institute (Shenzhen, China). After initial filtering of low quality reads and adaptor removal, clean reads were de novo assembled using Trinity. The transcriptomic data has been submitted to NCBI Sequence Read Archive database (SRR11184806 and SRR11358229, BioProject PRJNA608239 for T. molitor and SRR11178058 and SRR11178059, BioProject PRJNA608269 for
1 MLSLPI I I T IFLVRVTWAYNEELYSLSENLDPYSYPSEYQEDSDFDVRRR NNNNFLRFGRSGGTNYDVEYDD 72 1 MVPLAL I ITTCL I HLTWSYNEELYPLSDPDSSYLYPEDVPDETEFEIHRRNNNNFLRFGRSG.RKYDSEYED 71 1 MVPFAILILTLI IQLASGYNNEDFYSDNFDG . . FEEPSEEVSDMEVRRRNSN.FLRFGRSG. . PNYEYED 65

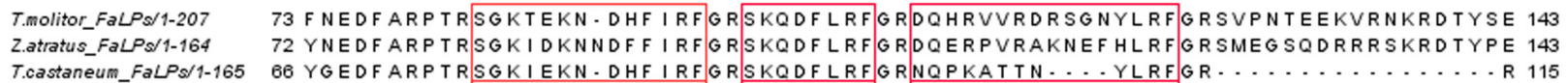

T.molitor_FaLPS1-207 144 F KRGGSNFMRFGR NSNFLRFGRNNEMTATSDPEKVQQLQESPLVQLLSELLEHIKKGQDKNRIV

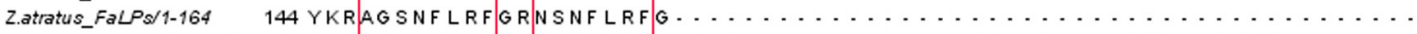
T.castaneum_FaLPS/1-165 116 NKRDTSNFLRFGRNSNFLRFGRNNES......... SYESPLVQLLSSLKKEENKQRIV...

207 164 165

FIGURE 1 | Sequence alignment of FaLPs precursors from T. molitor (T. molitor_FaLPs - this study), Z. atratus (Z. atratus_FaLPs - this study) and T. castaneum (T. castaneum_FaLPS, EFA02863), all from Tenebrionidae. Peptides present in the precursor are marked in red boxes. 
Z. atratus) and were used for local tblastn withFaLPs precursor sequence from T. castaneum (EFA02863) and FaLPs receptor sequence from T. castaneum (NP_001280540.1) to find T. molitor and $Z$. atratus FaLPs precursor and receptor sequence.

\section{Receptor Transcript Distribution}

Transcript profiles of Tenmo-FMRFR and Zopat-FMRFR were determined by reverse transcriptase PCR (RT-PCR) in various tissues of adults. RT-PCR was performed according to a modification of the method described by Marone et al. (2001). Suitable tissues/organs (nervous system - brain, retrocerebral complex CC/CA and ventral nerve cord, and heart, hindgut, ejaculatory duct and oviduct) after dissection were transferred to $150 \mu \mathrm{L}$ of RNA lysis buffer (Zymo Research, United States) and homogenized for $3 \mathrm{~min}$ using a pellet homogenizer. The homogenized tissues/organs were immediately frozen in liquid nitrogen and then stored at $-80^{\circ} \mathrm{C}$. A Quick-RNA ${ }^{\circledR}$ Mini Prep kit (Zymo Research, United States) was used for RNA isolation. The RNA concentration was determined with a Synergy H1 Hybrid Multi-Mode Microplate Reader (BioTek, United States). Reverse transcription of the same amount of isolated RNA to cDNA was accomplished using the RevertAid ${ }^{\mathrm{TM}}$ Reverse Transcriptase kit (Thermo-Fisher Scientific, United States) according to the manufacturer's protocol. PCR analyses were conducted using a T100 TM Thermal Cycler (Bio-Rad, United States). The primers were designed based on sequences of Tenmo-FMRFR and Zopat-FMRFR using Primer3 software (Untergasser et al., 2012). The primer pair for Tenmo-FMRFR was created to amplify fragments of $120 \mathrm{bp}$ with the following sequences Fw $5^{\prime}$-AACATAATAGACACCTACTG$3^{\prime}$ and Rev 5'-CTTCTCACCGAATATCAC-3', whereas the primers for Zopat-FMRFR amplify fragment of $143 \mathrm{bp}$ and where Fw 5'-TACCTCCAGCTCTACCGCTT-3' and Rev $5^{\prime}$-AGGCCGATGAGGAGGTAGTT-3'. The primers were synthetized by the Institute of Biochemistry and Biophysics of the Polish Academy of Science (Warsaw, Poland). PCR was performed in a $10 \mu \mathrm{L}$ reaction volume containing $3.95 \mu \mathrm{L}$ of DNase/RNase-free water, $1 \mu \mathrm{L}$ of DreamTaq Green Buffer (Thermo-Fisher Scientific, United States), $1 \mu \mathrm{L}$ of $2 \mathrm{mM}$ dNTP, $1 \mu \mathrm{L}$ of $10 \mu \mathrm{M}$ forward primers, $1 \mu \mathrm{L}$ of $10 \mu \mathrm{M}$ reverse primers, $0.05 \mu \mathrm{L}$ of DreamTaq DNA polymerase (Thermo-Fisher Scientific, United States) and $2 \mu \mathrm{L}$ of cDNA. The obtained products were analyzed by electrophoresis using a $2 \%$ TAE agarose gel stained with ethidium bromide. The GeneRuler 100 bp DNA Ladder (Fermentas, United States) was run on each gel. Photos of the agarose gels were taken using ChemiDoc Touch (Bio-Rad, United States). PCR was with a minimum of five biological and three technical replicates. To confirm our results, the bands were sequenced with BigDye Terminator v3.1 on an ABI Prism 3130XL Analyzer (Applied Biosystems, Foster City, CA, United States) according to manufacturer's protocols by the Molecular Biology Techniques Laboratory (Faculty of Biology, Adam Mickiewicz University, Poznań) and compared with transcriptomic data. "No template control" and "no RT control" reactions were included in the analysis to ensure that there was no foreign DNA or genomic DNA contamination.

\section{In vitro Visceral Organs Contraction Bioassays}

The heart bioassay was performed by microdensitometric whereas the oviduct, ejaculatory duct and hindgut bioassay by a video microscopy techniques as described previously (Marciniak and Rosinski, 2010; Marciniak et al., 2011). In all bioassays, eight peptide concentrations were tested ranging from $10^{-12}$ to $10^{-5} \mathrm{M}$. Proctolin as a positive control in concentration $10^{-7} \mathrm{M}$ was used (Supplementary Table S1). In brief, in the heart bioassay a semi-isolated heart preparations in superfusion chamber were mounted under the microdensitometer MD-100 (Carl Zeiss, Germany), whereas in video microscopy technique isolated visceral organs on Sylgard filled chamber were placed under the Olympus SZX12 stereomicroscope equipped with a SD30 camera. In all bioassays, an open perfusion system was used, with an injection port (for peptides) $70 \mathrm{~mm}$ above the superfusion chamber. The organ was subjected to a constant perfusion with fresh saline at the rate of about $140 \mu \mathrm{L} / \mathrm{min}$. All tested samples were applied at the injection port with a Hamilton syringe. Many pulse applications of samples could be sequentially assayed in a single preparation. After the initial $15 \mathrm{~min}$ stabilization, the activity of the isolated organ was recorded for $2 \mathrm{~min}$. Next the peptide was applied and the heart activity was recorded for a further $2 \mathrm{~min}$. In the heart bioassay, the apparatus equipped with photocell counts optically every contraction of the heart, and being connected with microdensitometer register system, computer generated the cardiogram. In the video microscopy technique, first the video recordings of superfused organs were performed and then analyzed with the edge tracking software (AnTracker) to create a trace of the movement of the side edge of the organ.

\section{Statistics}

All statistical comparisons non-parametric $t$-tests (MannWhitney test) were performed with usage of Graph Pad Prism 6 software (AMU license). Results were considered statistically significant with $p<0.05$. Prior to the analysis Shapiro-Wilk normality test was done for all of the groups.

\section{RESULTS}

\section{Analysis of T. molitor and Z. atratus FaLPs Precursor and FMRFR Sequences}

A blast search in the transcriptomes assemblies of T. molitor and $Z$. atratus yielded the FaLPs precursors of T. molitor and $Z$. atratus. Precursors were similar in structure to the homologous precursor from $T$. castaneum and encode six peptides of which two are identical in all of the beetles (Figure 1).

The BLAST search with local databases of the transcriptomic assemblies of $T$. molitor and $Z$. atratus brains and retrocerebral complexes yielded one open reading frame of a putative FaLPs receptor in each assembly. The receptor in T. molitor is $1,278 \mathrm{bp}$ and in $Z$. atratus is $1,266 \mathrm{bp}$ (Figure 2). Both display the seven transmembrane domains typical for GPCRs (Bass et al., 2014) with an $\mathrm{N}$-terminal ligand binding region 
$\begin{array}{ll}\text { Tenmo-FMRFR/1-426 } & 1 \text { MSTTTEFLNDSATFLNESTDSCLNDEDEYLQLYRF ITNGLLLNIIGVLGILGNIISMIILSRPQMRSSINYLLIGLARIDTVLIVTSILLFGLPGIY } 97 \\ \text { Zopat-FMRFR/1-422 } & \text { 1 MSTTDTYAFQNDTPFNLSLDSCLNDEEKLQLYRFFTNGLLLNIIGILGILGNIISMIILSRPQMRSSINYLLIGLARIDTVLILTSILLFGLPGIY 97 }\end{array}$

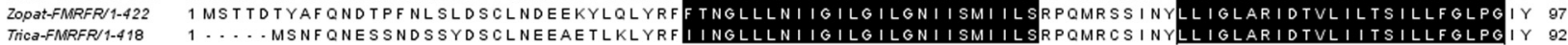

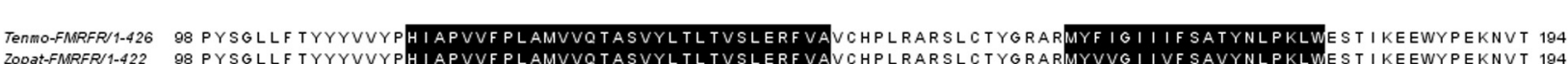

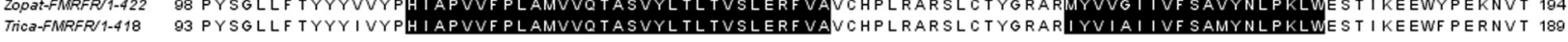

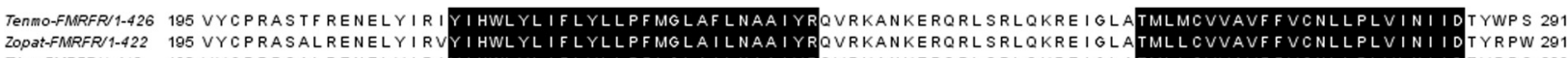
Trica-FMRFR/1-418 190 VYCPRPSALRENELYIRI Y I HWLYL IFLYLLPFLGLA ILNAAIYRQVRKANKERQRLSRLQKREIGLATMLLCVVAVFFVCNLLPLVLN I DTYRPS 280

Tenmo-FMRFR/1-426 292 LNLSRLVNTSNLLVTINSSVNF I IYVIFGEKFKRLFLVLF CRNSLFGTGRESPDGATHEDSFMSNGDRQSLRLHRQNTNISRNGMSGRMNGSGREKK 388 Zopat-FMRFR/1-422 292 WNLS I LVNT SNLLVT INSSVNF I I YVI I GEKFKRLFLVLF CNNSLFGTGRESPDGATHEDSFMSNGDRQSLRLHRQNTT I SRNGMSGRMNGS.... Q 384 TTica-FMRFR/1-418 287 WDMP I LVNT SNLLVT INSSVNF I IYVIFGEKFKRLFLLLF CNNSLFGTGRESPDGATHDDSFMSNGDRQSLRLHRHN....RNGMSTRMNGSERDKK 379

TENmO-FMRFR/1-426 389 RS.RCRASSPGPCVYYPANRTSKEITSAYTTQTSILGPD Zopat-FMRFR/1-422 385 KK.RSRASSPGPCVYYPANRGSKEI PSAYTTQTSLSGPD

THiCa-FMRFR/1-418 380 KGGRSRASSPGPCVYYPANRASKEITIAYTTQTSLSAPD

FIGURE 2 | Alignment of the FMRFRs sequences from T. molitor (Tenmo-FMRFR), Z. atratus (Zopat-FMRFR), and T. castaneum (Trica-FMRFR), all from the Tenebrionidae family. Predicted seven transmembrane domains are highlighted in black.

and a C-terminal intracellular region. The comparison of the putative sequences showed that there is a very high degree of similarity (90\%) between Tenmo-FMRFR and Zopat-FMRF. Less but also very high similarity was observed between TenmoFMRFR and Trica-FMRFR $-84 \%$ and between Zopat-FMRFR and Trica-FMRFR $-86 \%$.

\section{Distribution of FMRFR Transcripts in Different Tissues of T. molitor and \\ Z. atratus}

In order to check whether the peptide is able to influence the visceral organs directly, we examined the FMRFR spatial distribution by RT-PCR. As a positive control, we used nervous tissues, as FMRFR was previously shown to be present in this tissue in other insects, such as D. melanogaster (Meeusen et al., 2002). Analysis of FMRFR transcripts distribution in both species revealed that it is present in all tissues used for RNA isolation. It proves that FMRFR is present in the nervous system as well as various visceral organs of tenebrionid beetles (Figure 3). Despite the fact that quantitative analysis was not performed, the band intensity indicates that the level of the transcript may vary between tissues tested and, as expected, is the highest in the nervous system of both beetles and much lower in the digestive tract and the reproductive tract (Figure 3).

\section{Effect of FMRF6 on the T. molitor Visceral Muscles Contractility}

Application of a synthetic tenebrionid FMRF6 peptide during superfusion with physiological saline caused differentiated effects in frequency of contractions of the heart, hindgut, ejaculatory duct and oviduct of T. molitor beetle (Figure 4). The observed effects were organ-specific.

The T. molitor adult heart rhythm in vitro remained regular during superfusion with saline and showed on average 124 beats/min. Application of FMRF6 caused immediate, dosedependent and reversible slight decrease of the heart contractile activity. The significant cardioinhibition was caused only by the highest tested concentration $-10^{-5} \mathrm{M}$ (Figure 4A). All other concentrations from $10^{-12}$ to $10^{-6} \mathrm{M}$ caused no effects.

The hindgut contractions of adult $T$. molitor remained irregular during superfusion with saline (5 contractions/min on average). Contrary to the heart, application of the FMRF6 peptide to the hindgut caused an increase in contraction frequency (Figures 4B, 5B) in almost all of tested concentrations apart from
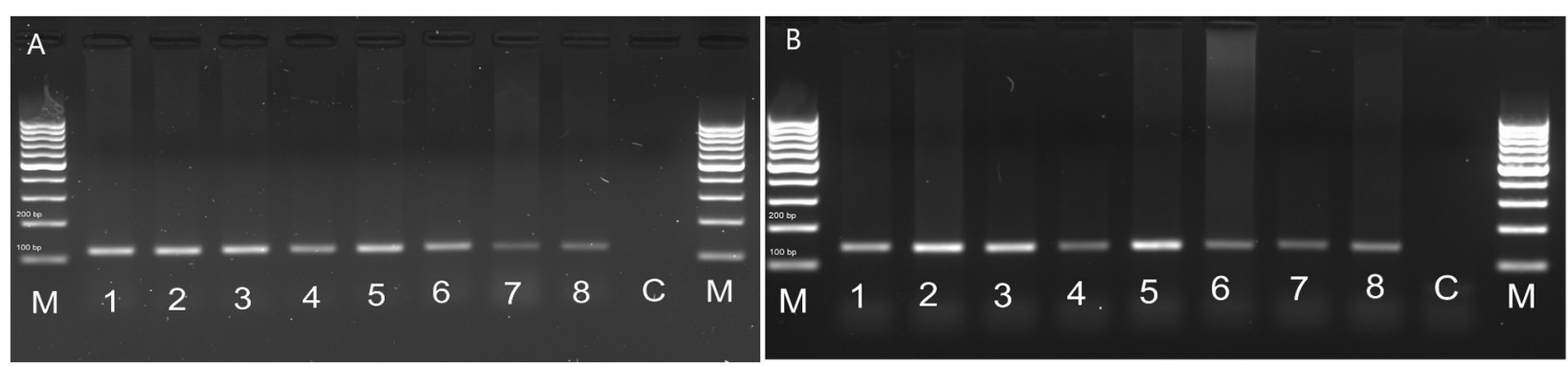

FIGURE 3 | Distribution of FMRFR transcript in different tissues of T. molitor (A) and Z. atratus (B). 1, whole body; 2, brain; 3, ventral nerve cord; 4, retrocerebral complex; 5, heart; 6 , hindgut; 7 , ejaculatory duct; 8, oviduct; $\mathrm{C}$, control $\mathrm{H}_{2} \mathrm{O}$; $\mathrm{M}$, marker. 

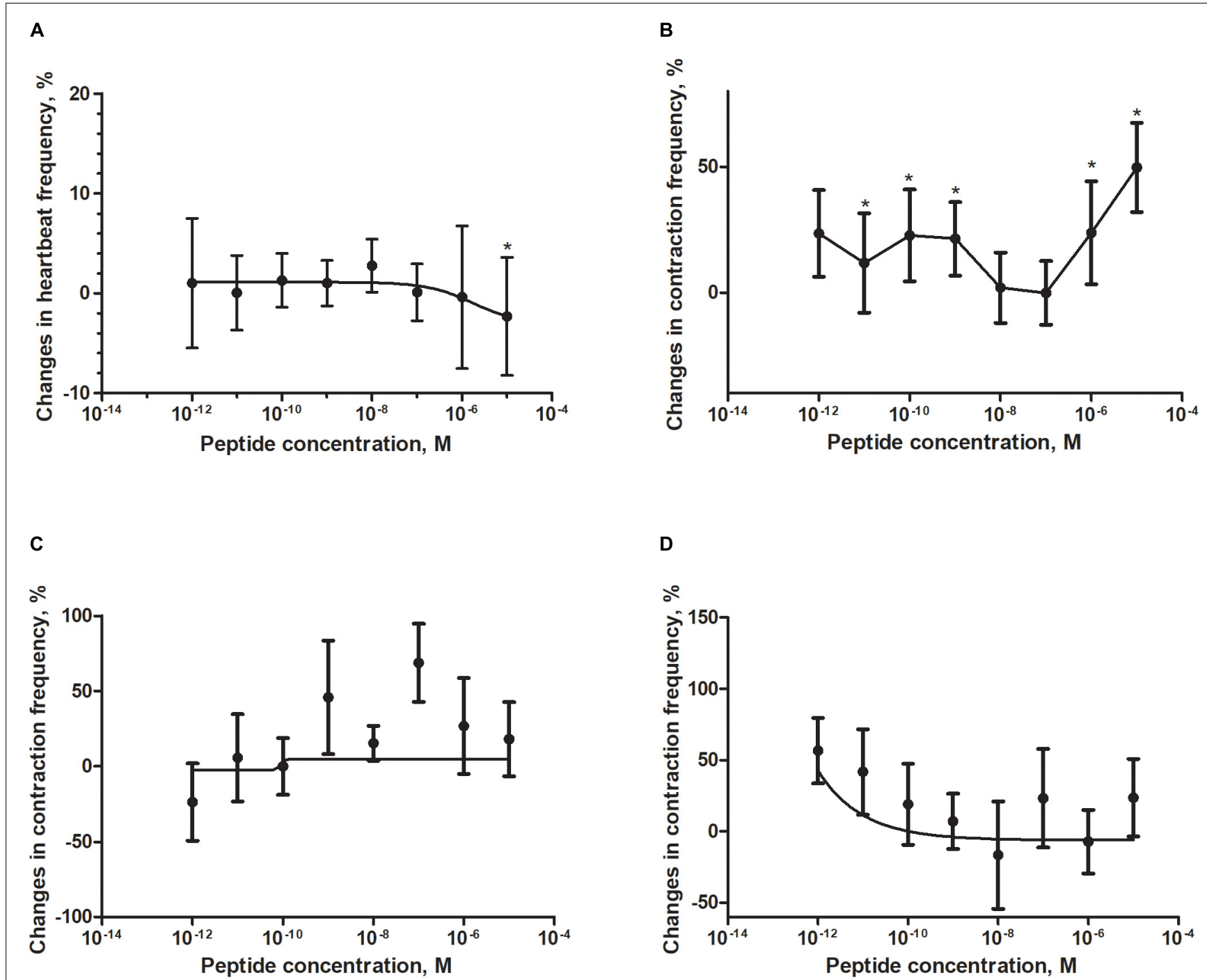

FIGURE 4 | Changes compared to control in the contractions frequency of heart (A), hindgut (B), ejaculatory duct (C), and oviduct (D) of adult T. molitor beetle after application of FMRFa. Mean \pm SEM are given from at least eight determinations. Statistically significant differences ( $p \leq 0.05)$ in the contractions frequency from control (saline application) are indicated by asterisks ( $t$-Student test) $n=10-15$.

$10^{-8}$ to $10^{-7} \mathrm{M}$. The highest myotropic effect (51\% stimulation) was observed after application of the highest concentration $10^{-5}$ M. Remarkably in lower concentrations $\left(10^{-12}-10^{-11} \mathrm{M}\right)$ less potent myostimulation also was observed with an effect half that observed after $10^{-5} \mathrm{M}$ application.

The T. molitor ejaculatory duct contractions were very irregular during superfusion with physiological saline with the level of 2 contraction/min on average (Figure 4C). Application of FMRF6 peptide caused no statistically significant effects in the contractions frequency, however in single repetitions stimulation of $70 \%$ was sometimes observed.

Contrary to the ejaculatory duct, the oviduct of T. molitor females contracted more regular with an average of 7 contractions/min (Figure 4D). FMRF6 caused dose-dependent miostimulatory effects on the oviduct. Similarly to the hindgut bioassay, the highest increase in contraction frequency (50\%) was observed in lower concentrations $\left(10^{-12}-10^{-11} \mathrm{M}\right)$. In higher concentration ranges, the stimulatory effect was not so evident.

\section{Effect of FMRF6 on the Z. atratus Visceral Muscles Contractility}

In in vitro bioassays with isolated $Z$. atratus visceral organs, peptide FMRF6 caused differentiated myotropic effects. Similar to other insect evaluated, the effect of FMRF6 in Z. atratus was organ-specific (Figure 6).

Semi-isolated heart of adult Z. atraus during superfusion with physiological saline showed regular rhythm with an average 35 beats/min, which was much slower than that of T. molitor (Figure 5A). In contrast to T. molitor, addition of the peptide resulted in a concentration-dependent positive chronotropic effects (increase in heartbeat frequency). The 


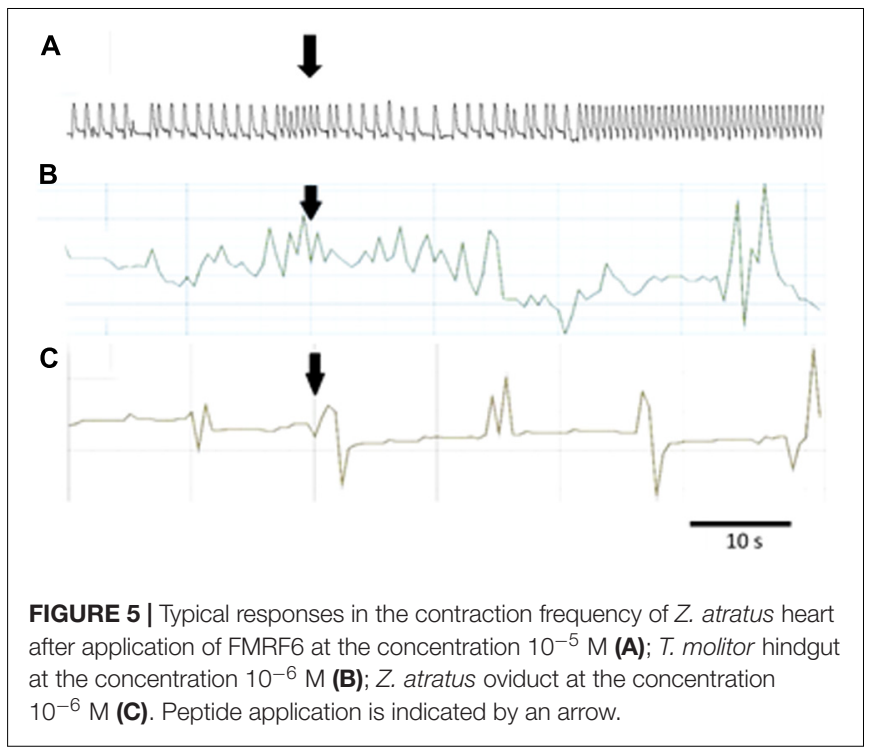

maximal effect was observed after application of one of the highest concentrations $10^{-6} \mathrm{M}$, as was shown for the previously described species, where also only the highest concentrations were cardioactive (Figure 6A).

The highest tested concentration $\left(10^{-5} \mathrm{M}\right)$ also was myostimulatory when applied on the isolated hindgut of $Z$. atratus. Average contraction frequency of the hindgut during superfusion was around 10 and increased to $193 \%$ after its application. Remarkably all other concentrations tested $\left(10^{-12}\right.$ $10^{-6} \mathrm{M}$ ) showed also an increase in contraction frequency of on average $37 \%$ (Figure 6B).

The irregular control ejaculatory duct contraction during superfusion with saline was on average 3 contractions/min. Similar to T. molitor, application of FMRF6 resulted in an increase in contraction frequency but the effect was much stronger than in T. molitor. The highest increase in contraction frequency (48\%) was measured after application of $10^{-7} \mathrm{M}$. All tested concentrations between $10^{-9}$ and $10^{-6} \mathrm{M}$ were myostimulatory with different efficiency (Figure 6C). Only the
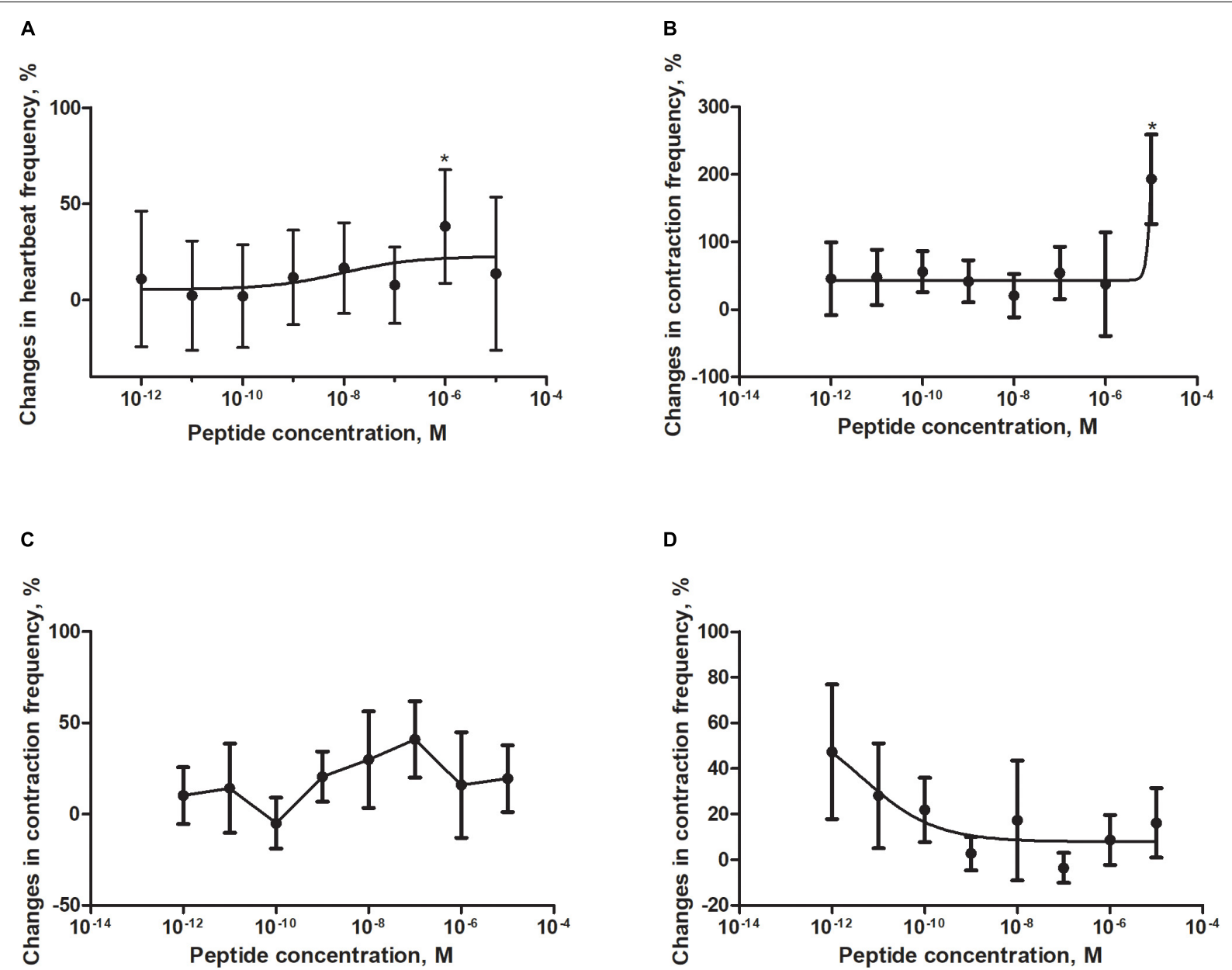

FIGURE 6 | Changes compared to control in the contractions frequency of heart (A), hindgut (B), ejaculatory duct (C), and oviduct (D) of adult Z. atratus after application of FMRF6. Mean \pm SEM are given from at least eight determinations. Statistically significant differences $(p \leq 0.05)$ in the contractions frequency from control (saline application) are indicated by asterisks ( $t$-Student test). 
concentration of $10^{-10} \mathrm{M}$ was inactive when applied on the oviduct (Figure 6C).

The last tested visceral organ - the oviduct from $Z$. atratus, had a control contraction rhythm at the level of 13 contractions/min on average. Similar to T. molitor, application of FMRF6 caused an increase in the contraction frequency but only in the lower tested concentration ranges (Figure 6D). The strongest effect was obtained after application of the lowest $10^{-12} \mathrm{M}$ concentration and the increase in contractions frequency was about $47 \%$. The highest concentrations from $10^{-9}$ to $10^{-5} \mathrm{M}$ caused no effect (Figure 5C).

\section{DISCUSSION}

The present study expands the knowledge about the physiological role of FaLPs in the largest group of insects - Coleoptera. Here, we have examined the role of a $\mathrm{N}$-terminally extended bioanalogue of FMRFa in the regulation of visceral organs contractions in $T$. molitor and $Z$. atratus beetle. We used a synthetic peptide FMRF6 (NSNFLRFa), which was identical in the FaLPs precursors of both tested beetles. We showed in in vitro bioassays, that the peptide was mainly myostimulatory and, with the exception of the T. molitor heart, it increased the frequency of contractions of beetles muscles organs with different efficiency. The effects appear to be organ-specific. An oviduct of both beetle species turned out to be the most sensitive to the peptide. The peptide acts via the putative GPCR characterized in both species.

FaLPs signaling has been studied in variety of insect species, including mosquitoes (Hillyer et al., 2014), stick insects (Lange et al., 2009), kissing bugs (Sedra and Lange, 2014), or flies (Merte and Nichols, 2002). However, the receptor for FaLPs was first discovered (Cazzamali and Grimmelikhuijzen, 2002) and very well characterized only in D. melanogaster (Maynard et al., 2013; Milakovic et al., 2014). As for most of the receptors activated by neuropeptides, FMRFRs belong to G-protein coupled receptors with seven transmembrane helixes, $\mathrm{N}$-terminal extracellular segment and the intracellular C-terminus responsible for interactions with $\mathrm{G}$ proteins (Hauser et al., 2008). Moreover, a detailed analysis of insect FMRFR indicated that all belong to the subfamily A - rhodopsin like GPCRs thus far identified in flies, mosquitoes, moths and kissing bugs (Rasmussen et al., 2015). In beetles, the first FMRFR was identified in the model species for this order - T. castaneum (Hauser et al., 2008). Also, the receptor predicted in this study resembles this type of receptors containing some of typical rhodopsin-like amino acid patterns in its seven transmembrane domains: GN in helix 1, NLX3-DX8P in helix 2, SX3LX2IX2DRY in helix 3, WX8P in helix 4, FX2PX7Y in helix 5, FX3WXP in helix 6 and NPX2YX6F in helix 7 (Figure 2; Bass et al., 2014). Bioinformatical analysis demonstrated that the sequence similarity within tenebrionid beetles as expected is high.

The spatial tissue distribution of FMRFR was first studied in D. melanogaster (Meeusen et al., 2002). These authors showed that Drome-FMRFR is present in the nervous system (brain), guts and ovaries of larva and adult D. melanogaster, as well as trachea and fat body (Meeusen et al., 2002), suggesting that FaLPs might be involved in regulation of various physiological processes and in agreement with our study. We showed that the FaLPs receptor predicted here is present in the nervous system (brain, ventral nerve cord and retrocerebral complex $\mathrm{CC} / \mathrm{CA}$ ) as well as in all tested visceral organs suggesting the role of FaLPs in the regulation of functions of these organs. The data also is partially in agreement with studies performed on mosquitoes (Hillyer et al., 2014). The highest expression of FMRFR in Anopheles gambiae occurred in the head and thorax of this insects (Hillyer et al., 2014). It is surprising that in A. gambiae the expression level of FMRFR was so low in the abdomen. As in numerous insects, FaLPs immunoreactivity was observed in abdominal ganglia, midguts, and other visceral organs as well as in abdominal neural processes in D. melanogaster, $R$. prolixus, Schistocerca gregaria, Phormia regina (blow fly) and other insects (Myers and Evans, 1985; Nichols et al., 1995; Sedra and Lange, 2014), and therefore it was expected that the FaLPs receptors will be highly expressed in the abdomen. Probably this is the case in D. melanogaster and in the beetles studied here but not in the mosquito. This differences might be connected with role of FaLPs in visceral organs physiology. These beetles and mosquitos differ significantly in how they ingest and process food.

FaLPs are neuropeptides which are known to be mainly myoactive (Merte and Nichols, 2002). The best established activity of these peptides is their involvement in the regulation of the heart rhythm (Chowanski et al., 2016). The cardioactive properties of different FaLPs were shown in variety of insect species including S. gregaria, B. extradentatum, D. melanogaster and A. gambiae (Cuthbert and Evans, 1989; Nichols, 2006; Lange et al., 2009; Hillyer et al., 2014). These studies have not been performed on beetles before now. Most insect species exhibit dose-dependant cardioacceleratory properties and our study is partially in agreement. FMRF6 was cardio acceleratory on the heart of $Z$. atratus. Surprisingly the same peptide was cardio inhibitory on the $T$. molitor heart in the high concentration ranges. In the very high concentrations $\left(10^{-3}-10^{-2} \mathrm{M}\right)$, one of the N-terminally extended FaLPs was also cardioinhibitory in mosquitoes (Hillyer et al., 2014). However, in A. gambiae a FaLP peptide exerted bimodal effect. It was cardio acceleratory in low concentrations whereas in our study it exerted no cardiotropic effects.

Apart from the heart, FaLPs were shown to be myoactive on different visceral organs such as the gut and reproductive tract (ejaculatory duct and oviduct) of tenebrionids. As in the heart, the peptide was shown to be mostly myostimulatory. The results obtained in this study are in agreement with results obtained in other species, especially the extensively studied female reproductive tract. It was shown for example that various parts of the $R$. prolixus reproductive tract are stimulated by N-terminally extended FaLPs and the effect is similar to the FMRFa peptide (Sedra and Lange, 2014, 2016). In beetles, no previous studies were available for FaLPs in terms of the regulation of contractility of visceral organs. Previous studies examined only the tetrapeptide FMRFa on the motility of T. molitor and Z. atratus ejaculatory duct and oviduct (Marciniak and Rosinski, 2010). We showed that contractions of ejaculatory duct was inhibited whereas oviduct contractions were mainly stimulated after application of FMRFa in these tenebrionids. 
In both cases, the effects were bimodal and dose-dependent (Marciniak and Rosinski, 2010). The different responses of the ejaculatory duct and oviduct to FMRFa and FMRF6 (NSNFLRFa) is probably due to difference in amino acid - $M$ changed to $L$, which affects receptor binding.

In summary, we demonstrated the myostimulatory activity of N-terminally extended FaLP in two tenebrionid beetles. The tested peptide NSNFLRFa is present in both insects in the sequence of the FaLPs precursor and presumably act via G-protein coupled receptors, which were also predicted and identified in both species. We showed that in both beetles this peptide is myostimulatory to the gut, ejaculatory duct and oviduct and the effect is dose-dependent in almost all cases. The data suggest that FaLPs regulate functioning of this organs thus are involved in different physiological processes. The role of FaLPs in cardiac physiology is more complex. The effect of peptide is dose-dependent and species specific.

\section{DATA AVAILABILITY STATEMENT}

The transcriptomic data has been submitted to NCBI Sequence Read Archive database (SRR11184806 and SRR11358229, BioProject PRJNA608239 for T. molitor and SRR11178058 and SRR11178059, BioProject PRJNA608269 for Z. atratus).

\section{REFERENCES}

Audsley, N., and Down, R. E. (2015). G protein coupled receptors as targets for next generation pesticides. Insect Biochem. Mol. Biol. 67, 27-37. doi: 10.1016/j. ibmb.2015.07.014

Bass, C., Katanski, C., Maynard, B., Zurro, I., Mariane, E., Matta, M., et al. (2014). Conserved residues in RF-NH(2) receptor models identify predicted contact sites in ligand-receptor binding. Peptides 53, 278-285. doi: 10.1016/j.peptides. 2013.06.009

Cazzamali, G., and Grimmelikhuijzen, C. J. (2002). Molecular cloning and functional expression of the first insect FMRFamide receptor. Proc. Natl. Acad. Sci. U.S.A. 99, 12073-12078. doi: 10.1073/pnas.192442799

Chowanski, S., Lubawy, J., Urbanski, A., and Rosinski, G. (2016). Cardioregulatory functions of neuropeptides and peptide hormones in insects. Protein Pept. Lett. 23, 913-931. doi: 10.2174/0929866523666160728102842

Coast, G. M., and Schooley, D. A. (2011). Toward a consensus nomenclature for insect neuropeptides and peptide hormones. Peptides 32, 620-631. doi: 10.1016/ j.peptides.2010.11.006

Cuthbert, B. A., and Evans, P. D. (1989). A comparison of the effects of fmrfamidelike peptides on locust heart and skeletal-muscle. J. Exp. Biol. 144, 395-415.

Hauser, F., Cazzamali, G., Williamson, M., Park, Y., Li, B., Tanaka, Y., et al. (2008). A genome-wide inventory of neurohormone GPCRs in the red flour beetle Tribolium castaneum. Front. Neuroendocrinol. 29:142-165. doi: 10.1016/ j.yfrne.2007.10.003

Hillyer, J. F., Estevez-Lao, T. Y., and De La Parte, L. E. (2014). Myotropic effects of FMRFamide containing peptides on the heart of the mosquito Anopheles gambiae. Gen. Compar. Endocrinol. 202, 15-25. doi: 10.1016/j.ygcen.2014.03. 048

Lange, A. B., Calvin, A., and Da Silva, R. (2009). Neuropeptides modulate the heart of the stick insect Baculum extradentatum. Ann. N. Y. Acad. Sci. 1163, 448-450. doi: 10.1111/j.1749-6632.2008.03658.x

Li, B., Predel, R., Neupert, S., Hauser, F., Tanaka, Y., Cazzamali, G., et al. (2008). Genomics, transcriptomics, and peptidomics of neuropeptides and protein hormones in the red flour beetle Tribolium castaneum. Genome Res. 18, 113-122. doi: 10.1101/gr.6714008

\section{AUTHOR CONTRIBUTIONS}

PM and GR contributed conception of the study. PM designed the study, analyzed the data, and wrote the manuscript. PM, WW, and MS performed the physiological experiments. JP-B and SC performed the molecular experiments. MK performed the peptide synthesis. All authors contributed to manuscript, read and approved the submitted version.

\section{FUNDING}

This study was supported by project NCN2013/09/D/NZ3/00002 from National Science Center Poland.

\section{ACKNOWLEDGMENTS}

We would like to thank Beata Koralewska for technical assistance.

\section{SUPPLEMENTARY MATERIAL}

The Supplementary Material for this article can be found online at: https://www.frontiersin.org/articles/10.3389/fphys. 2020.00456/full\#supplementary-material

Lubawy, J., Marciniak, P., Kuczer, M., and Rosinski, G. (2018). Myotropic activity of allatostatins in tenebrionid beetles. Neuropeptides 70, 26-36. doi: 10.1016/j. npep.2018.05.003

Marciniak, P., Grodecki, S., Konopinska, D., and Rosinski, G. (2008). Structureactivity relationships for the cardiotropic action of the Led-NPF-I peptide in the beetles Tenebrio molitor and Zophobas atratus. J. Pept. Sci. 14, 329-334. doi: $10.1002 /$ psc.933

Marciniak, P., Kuczer, M., and Rosinski, G. (2011). New physiological activities of myosuppressin, sulfakinin and NVP-like peptide in Zophobas atratus beetle. J. Comp. Physiol. B. 181, 721-730. doi: 10.1007/s00360-0110563-5

Marciniak, P., and Rosinski, G. (2010). Comparison of proctolin and FMRFamide actions on the motility of male and female beetle reproductive tracts. Invert. Reproduct. Dev. 54, 1-6.

Marone, M., Mozzetti, S., De Ritis, D., Pierelli, L., and Scambia, G. (2001). Semiquantitative RT-PCR analysis to assess the expression levels of multiple transcripts from the same sample. Biol. Proc. Online 3, 19-25. doi: 10.1251/ bpo 20

Marques, G., Haerry, T. E., Crotty, M. L., Xue, M., Zhang, B., and O'connor, M. B. (2003). Retrograde Gbb signaling through the Bmp type 2 receptor wishful thinking regulates systemic FMRFa expression in Drosophila. Development 130, 5457-5470. doi: 10.1242/dev.00772

Maynard, B. F., Bass, C., Katanski, C., Thakur, K., Manoogian, B., Leander, M., et al. (2013). Structure-activity relationships of FMRF-NH2 peptides demonstrate A role for the conserved $\mathrm{C}$ terminus and unique $\mathrm{N}$-terminal extension in modulating cardiac contractility. PLoS One 8:e75502. doi: 10.1371/journal. pone.0075502

Meeusen, T., Mertens, I., Clynen, E., Baggerman, G., Nichols, R., Nachman, R. J., et al. (2002). Identification in Drosophila melanogaster of the invertebrate $G$ protein-coupled FMRFamide receptor. Proc. Natl. Acad. Sci. U.S.A. 99, 15363-15368. doi: 10.1073/pnas.2523 39599

Merte, J., and Nichols, R. (2002). Drosophila melanogaster FMRFamide-containing peptides: redundant or diverse functions? Peptides 23, 209-220. doi: 10.1016/ s0196-9781(01)00598-8 
Milakovic, M., Ormerod, K. G., Klose, M. K., and Mercier, A. J. (2014). Mode of action of a Drosophila FMRFamide in inducing muscle contraction. J. Exp. Biol. 217, 1725-1736. doi: 10.1242/jeb.096941

Myers, C. M., and Evans, P. D. (1985). An Fmrfamide antiserum differentiates between populations of antigens in the ventral nervous-system of the locust, Schistocerca-Gregaria. Cell Tissue Res. 242, 109-114. doi: 10.1007/BF00214659

Nichols, R. (2006). FMRFamide-related peptides and serotonin regulate Drosophila melanogaster heart rate: mechanisms and structure requirements. Peptides 27, 1130-1137. doi: 10.1016/j.peptides.2005.07.032

Nichols, R., Mccormick, J., Lim, I., and Caserta, L. (1995). Cellular expression of the Drosophila melanogaster FMRFamide neuropeptide gene product DPKQDFMRFamide. Evidence for differential processing of the FMRFamide polypeptide precursor. J. Mol. Neurosci. 6, 1-10. doi: 10.1007/BF02736754

Pandit, A. A., Davies, S. A., Smagghe, G., and Dow, J. A. T. (2019). Evolutionary trends of neuropeptide signaling in beetles - A comparative analysis of Coleopteran transcriptomic and genomic data. Insect Biochem. Mol. Biol. 114:103227. doi: 10.1016/j.ibmb.2019.103227

Price, D. A., and Greenberg, M. J. (1977). Structure of a molluscan cardioexcitatory neuropeptide. Science 197, 670-671.

Pyza, E., and Meinertzhagen, I. A. (2003). The regulation of circadian rhythms in the fly's visual system: involvement of FMRFamide-like neuropeptides and their relationship to pigment dispersing factor in Musca domestica and Drosophila melanogaster. Neuropeptides 37, 277-289. doi: 10.1016/j.npep.2003.06.001

Quennedey, A., Aribi, N., Everaerts, C., and Delbecque, J. P. (1995). Postembryonic development of Zophobas-Atratus Fab (Coleoptera. Tenebrionidae) under crowded or isolated conditions and effects of juvenile-hormone analog applications. J. Insect Physiol. 41, 143-152.

Rasmussen, M., Leander, M., Ons, S., and Nichols, R. (2015). Conserved molecular switch interactions in modeled cardioactive RF-NH2 peptide receptors: Ligand binding and activation. Peptides 71, 259-267. doi: 10.1016/j.peptides.2015.07. 012

Robb, S., and Evans, P. (1994). The modulatory effect of schistoflrfamide on heart and skeletal muscle in the locust Schistocerca Gregaria. J. Exp. Biol. 197, $437-442$.
Rosinski, G., Pilc, L., and Obuchowicz, L. (1978). Effect of hydrocortisone on growth and development of Larvae TenebrioMolitor. J. Insect Physiol. 24, 97-99. doi: 10.1016/0022-1910(78) 90017-3

Sedra, L., and Lange, A. B. (2014). The female reproductive system of the kissing bug, Rhodnius prolixus: arrangements of muscles, distribution and myoactivity of two endogenous FMRFamide-like peptides. Peptides 53, 140-147. doi: 10. 1016/j.peptides.2013.04.003

Sedra, L., and Lange, A. B. (2016). Cloning and expression of long neuropeptide $\mathrm{F}$ and the role of FMRFamide-like peptides in regulating egg production in the Chagas vector. Rhodnius prolixus. Peptides 82, 1-11. doi: 10.1016/j.peptides. 2016.05.003

Suggs, J. M., Jones, T. H., Murphree, S. C., and Hillyer, J. F. (2016). CCAP and FMRFamide-like peptides accelerate the contraction rate of the antennal accessory pulsatile organs (auxiliary hearts) of mosquitoes. J. Exp. Biol. 219, 2388-2395. doi: 10.1242/jeb.141655

Untergasser, A., Cutcutache, I., Koressaar, T., Ye, J., Faircloth, B. C., Remm, M., et al. (2012). Primer3-new capabilities and interfaces. Nucleic Acids Res. 40:e115. doi: 10.1093/nar/gks596

Veenstra, J. A. (2019). Coleoptera genome and transcriptome sequences reveal numerous differences in neuropeptide signaling between species. Peerj 7:e7144. doi: $10.7717 /$ peerj.7144

Conflict of Interest: The authors declare that the research was conducted in the absence of any commercial or financial relationships that could be construed as a potential conflict of interest.

Copyright (C) 2020 Marciniak, Witek, Szymczak, Pacholska-Bogalska, Chowański, Kuczer and Rosinski. This is an open-access article distributed under the terms of the Creative Commons Attribution License (CC BY). The use, distribution or reproduction in other forums is permitted, provided the original author(s) and the copyright owner(s) are credited and that the original publication in this journal is cited, in accordance with accepted academic practice. No use, distribution or reproduction is permitted which does not comply with these terms. 